\title{
Individual color functions
}

\author{
ARQ. M. L. F. de MATTIELLO \\ Laboratorio de Investigaciones Sensoriales, CONICET \\ Facultad de Medicina, Universidad de Buenos Aires, C.C. 53, Suc. 53, Argentina
}

\begin{abstract}
A total of 63 psychophysical lightness functions and 28 saturation functions of surface colors and grays were measured for $\mathbf{4 0}$ observers by the method of magnitude estimation. Although there is some variation in the size of the exponent from one person to another, individual functions of saturation and lightness can be described by the power law.
\end{abstract}

A number of experiments utilizing direct psychophysical methods (Guirao \& Mattiello, 1973; Indow \& S. S. Stevens, 1966; Mattiello \& Guirao, 1973, 1974; Panek \& S. S. Stevens, 1966) have demonstrated that luminance and colorimetric purity obey a power law. Working with surface colors, Guirao and Mattiello (1973) have shown that exponents range from 0.5 to 1 for luminance, and from 1.4 to 4 for purity, depending on the relations between chromatic variables. These authors have also pointed out that the exponent of the luminance function decreases at high and low wavelengths and at high and low purity levels, and that the exponent of the saturation function is lower at the ends of the spectrum than in its center.

It was the objective of the present investigation to demonstrate that the individual functions obtained in previous studies obey the power law, a characteristic that has already been shown for several other continua (Ekman \& Ȧkesson, 1964; Ekman, Hosman, \& Lindström, 1964; Künnapas, 1968; Schneider \& Lane, 1963; J. C. Stevens \& Guirao, 1964; Cross \& Lane, Note 1). We wished also to determine the variability of individual exponents, information that would allow the use of chromatic functions in the ophthalmological diagnosis of visual dysfunction.

\section{MATERIAL AND METHODS}

The individual functions to be analyzed come from previously reported studies (Guirao \& Mattiello, 1973; Mattiello \& Guirao, 1973, 1974). Details of method are therefore described only briefly here.

\section{Stimulus Characteristics}

The trichromatic specifications of the colors used have been reported in the studies cited. Specifications of average wavelength, chromatic purity, and luminance are shown in Tables 1 to 3.

Tests were carried out in daylight (approximately 1,000 lx) against a black background. The samples were opaque and were viewed at a $4^{\circ}$ visual angle. Samples used to determine achromatic functions were obtained by mixing black and white pigments in

The statistical analysis of the data of this work was carried out at the Centro de Cómputos, Hospital Escuela, Facultad de Medicina, Universidad de Buenos Aires. The author wishes to express her gratitude to Herschel W. Leibowitz for his help with the editing of this paper. different proportions. Samples used to determine chromatic functions with constant colorimetric purity were obtained by mixing the appropriate amounts of color and of gray (this having different degrees of luminance) in order to control saturation. Samples used to determine chromatic functions with variable colorimetric purity were obtained by mixing the hues with different amounts of black and white to achieve the desired saturation.

\section{Subjects}

Forty college students of both sexes with normal vision participated as subjects. Two of them took part in all the experiments.

\section{Procedure}

Magnitude estimation procedures were used throughout. Each subject reported two estimates per sample. No standard was utilized. In the case of lightness functions, the subjects were asked how much more or less light the stimuli were; in the case of saturation functions, the question was how much more or less color the samples had.

\section{RESULTS AND DISCUSSION}

The best fitting power functions for individual magnitude estimates as a function of luminance or saturation were determined by the method of least squares. The individual exponent $\left(\beta_{\mathrm{i}}\right)$, the individual coefficient of correlation $\left(r_{x y}\right)$, the mean exponent $\left(\bar{\beta}_{\mathrm{i}}\right)$, the standard error of the mean exponent $\left(\sigma_{\bar{\beta}_{i}}\right)$, and the percent standard error $(E)$ were obtained. Summary data are presented in Tables 1 through 3. Table 1 shows the values for achromatic functions

Table 1

Characteristics of Distributions of Individual Exponents $\left(\beta_{\mathbf{i}}\right)$ of Power Functions for Gray and Chromatic Lightness at Constant Colorimetric Purity-Mean $\left(\beta_{i}\right)$, Standard Error of the Mean $\left(\bar{\sigma}_{\bar{\beta}}\right)$, and Percent Standard Error $(E \%)$-and the Mean of the Correlation Coefficients $\left(\overline{\mathbf{X}}_{\mathbf{r}_{\mathbf{x y}}}\right)$ for Individual Functions

\begin{tabular}{lrcccc}
\hline & Gray & $\begin{array}{c}\text { Blue } \\
(470 \mathrm{~nm})\end{array}$ & $\begin{array}{c}\text { Green } \\
(553 \mathrm{~nm})\end{array}$ & $\begin{array}{c}\text { Yellow } \\
(574 \mathrm{~nm})\end{array}$ & $\begin{array}{c}\text { Red } \\
(622 \mathrm{~nm})\end{array}$ \\
\hline$\% \mathrm{R}$ & $4-80$ & $8-25$ & $13-47$ & $20-72$ & $6-40$ \\
$\mathrm{Pc}$ & & .07 & .39 & .69 & .16 \\
$\bar{\beta}_{\mathbf{i}}$ & .97 & 1.03 & .76 & .90 & .90 \\
$\sigma_{\beta_{\mathbf{i}}}$ & .095 & .126 & .108 & .128 & .131 \\
$\mathrm{E} \%$ & 9.7 & 10.3 & 14.2 & 14.2 & 14.5 \\
$\overline{\mathrm{X}}_{\mathbf{r}}$ & .985 & .950 & .962 & .954 & .978 \\
\hline
\end{tabular}

Note $-N=7$ for each hue. 
Table 2

Characteristics of Distributions of Individual Exponents $\left(\beta_{i}\right)$ of Power Functions for Chromatic Lightness at Variable Colorimetric Purity-Mean $\left(\bar{\beta}_{\mathfrak{i}}\right)$, Standard Error of the Mean $\left(\bar{\sigma}_{\beta_{i}}\right)$, and Percent Standard Error (E\%)-and the Mean of the Correlation Coefficients $\left(\overline{\mathbf{X}}_{\mathbf{r} x \mathbf{y}}\right)$ for Individual Functions

\begin{tabular}{lcccc}
\hline & $\begin{array}{c}\text { Blue } \\
(470 \mathrm{~nm})\end{array}$ & $\begin{array}{c}\text { Green } \\
(550 \mathrm{~nm})\end{array}$ & $\begin{array}{c}\text { Yellow } \\
(576 \mathrm{~nm})\end{array}$ & $\begin{array}{c}\text { Red } \\
(622 \mathrm{~nm})\end{array}$ \\
\hline$\% \mathrm{R}$ & $4.7-63$ & $17-76$ & $8.5-83$ & $7.7-54$ \\
$\mathrm{Pc}$ & $.04-.27$ & $.05-.67$ & $.31-.76$ & $.14-.59$ \\
$\bar{\beta}_{\mathrm{i}}$ & .46 & .54 & 1.11 & .61 \\
$\sigma_{\beta_{\mathrm{j}}}$ & .042 & .051 & .151 & .068 \\
$\mathrm{E} \%$ & 9.13 & 9.44 & 13.6 & 11.1 \\
$\overline{\mathrm{X}}_{\mathbf{r}_{\mathrm{xy}}}$ & .978 & .974 & .982 & .965 \\
\hline
\end{tabular}

Note $-N=7$ for each hue.

and for chromatic functions with constant colorimetric purity, and Table 2 for chromatic functions with variable colorimetric purity.

Figures 1 and 2 show, by way of example, the functions of two observers who participated in all experimental sessions.

For individual functions, the degree of dependence between the lightness and luminance variables is reflected in the coefficient of correlation $r_{x y}$. The high values of $r_{x y}$, which averages .97 , point to a close relationship between lightness and luminance, showing that the individual functions obey the power law.

It is also of interest to determine the variability of individual exponents, and what effect variations in hue and purity will have on this variability. Variability is reflected in the standard error of the mean exponent $\left(\sigma_{\bar{\beta}}\right)$. As $\sigma_{\overline{\beta_{i}}}$ may depend on the value of the exponent $\bar{\beta}_{\mathfrak{i}}$, the percent standard error,

$$
\mathrm{E}=\frac{\sigma_{\overline{\beta_{i}}}}{\bar{\beta}_{\mathrm{i}}} \times 100,
$$

is used in making comparisons. In Tables 1 and $2, \mathrm{E}$ ranges from $9 \%$ to $14 \%$. The smallest values of $E$ were found in grays and in lightness functions for blue, green, and red at variable colorimetric purities.

The same procedure was followed in analyzing the individual saturation functions displayed in Figure 3 and Table 3, taken from a previous study (Guirao \& Mattiello, 1973). As shown in Table 3, the average value of $r_{x y}$ is .95 . The magnitudes are similar to those for lightness. Again, power functions provide good fits to individual data. The measure $\mathrm{E}$, which ranges from $12 \%$ to almost $18 \%$, is slightly larger than the values for lightness.

Figure 3, which displays individual functions, clearly shows the variation in exponent for different hues and also that saturation exponents are higher

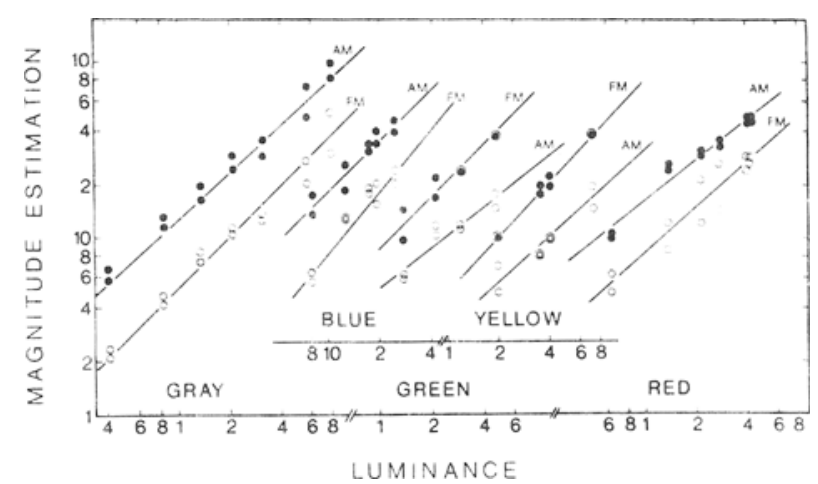

Figure 1. Individual lightness functions from two observers, for grays and four hues at constant colorimetric purity.

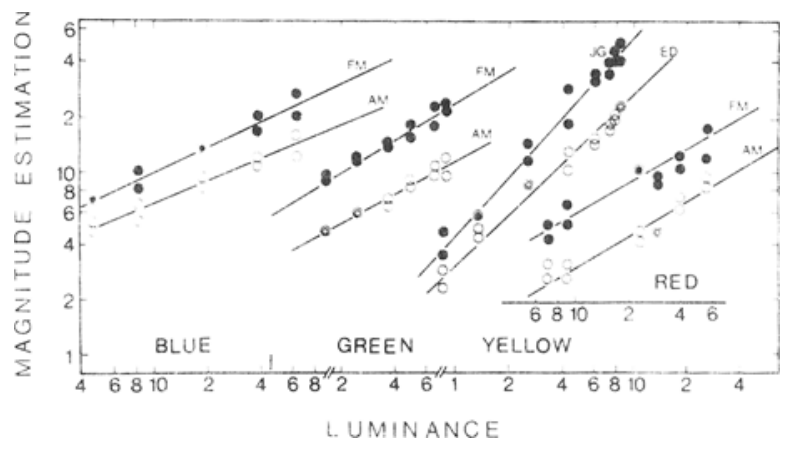

Figure 2. Individual lightness functions from four observers, for four hues at variable colorimetric purity.

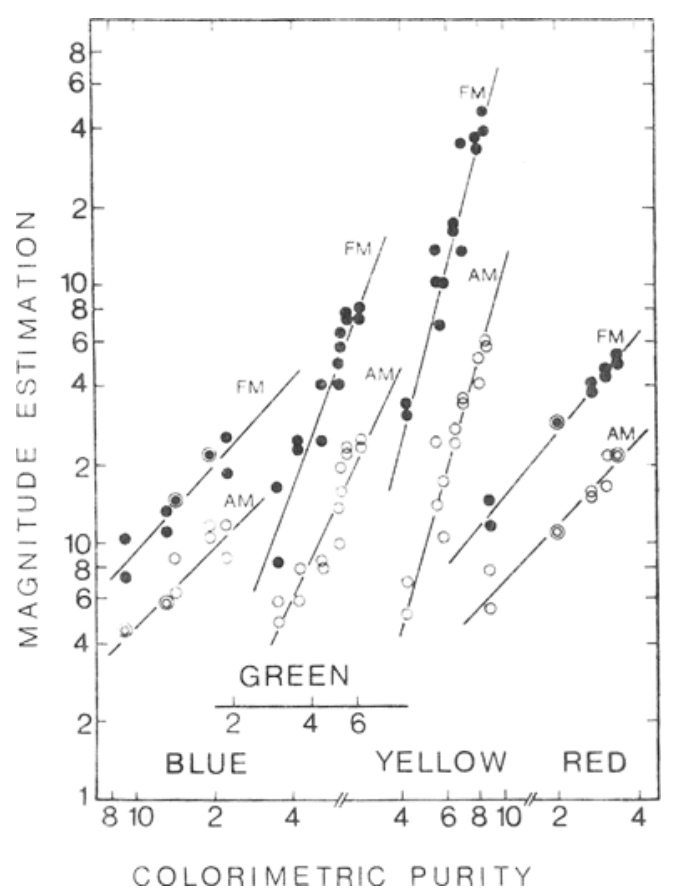

Figure 3. Individual saturation functions from two observers, for four hues at constant luminance. 
than those for lightness. The variability in exponents shown in Tables 1-3 is similar to the variability reported by other studies of individual psychophysical functions (Ekman \& Akesson, 1964; Ekman, Hosman, \& Lindström, 1964; Künnapas, 1968; Marks \& J. C. Stevens, 1966; Schneider \& Lane, 1963; J. C. Stevens \& Guirao, 1964; Cross \& Lane, Note 1). For example, variabilities of lightness exponents are similar to those obtained for brightness by Marks and J. C. Stevens (1966), and lower than the ones obtained for loudness by J. C. Stevens and Guirao (1964).

In another study, Mattiello and Gonnella (1975), using identical material and procedures, saturation functions for congenital and acquired anomalous subjects were determined. The individual exponents in the minor anomalies were double those for observers with normal vision, and five times higher than normal with the congenital anomalous. Since the largest value of $E$ recorded for saturation functions in normal subjects was $18 \%$, these differences are not plausibly accounted for by sampling error. Therefore, individual saturation functions at a constant level of luminance may be used successfully in the assessment of visual dysfunctions.

Finally, a comment should be made on departures from a power function of luminance functions for gray and yellow. Functions with one or two breaks are often found, as shown in Figure 4. Since surfaces with different reflecting power and illuminated with a constant light produce no adaptation changes, the breaks may be associated with changes in the subjective appreciation of, e.g., gray vs. black, or ochre or brown (obtained when yellow gets darker) vs. yellow vs. white (as yellow gets lighter). The author has observed that these breaks tend to occur when a set of chromatic or achromatic surfaces changes its perceptual qualities in a phenomenologically discontinuous manner (as in the transition from brown to yellow). This association of change in quality with change in exponent deserves further study.

Table 3

Characteristics of Distributions of Individual Exponents $\left(\beta_{\mathfrak{i}}\right)$ of Power Functions for Saturation-Mean $\left(\overline{\beta_{i}}\right)$, Standard Error of the Mean $\left(\sigma_{\beta_{i}}\right)$, and Percent Standard Error (E\%)-and the Mean of the Correlation Coefficients $\left(\overline{\mathbf{X}}_{\mathbf{r}_{\mathbf{x y}}}\right)$ for Individual Functions

\begin{tabular}{lrrrr}
\hline & $\begin{array}{c}\text { Blue } \\
(473 \mathrm{~nm})\end{array}$ & $\begin{array}{c}\text { Green } \\
(556 \mathrm{~nm})\end{array}$ & $\begin{array}{c}\text { Yellow } \\
(577 \mathrm{~nm})\end{array}$ & \multicolumn{1}{c}{$\begin{array}{c}\text { Red } \\
(630 \mathrm{~nm})\end{array}$} \\
\hline$\% \mathrm{R}$ & 19.5 & 27.5 & 53.5 & 21.5 \\
$\mathrm{Pc}$ & $.09-.22$ & $.30-.63$ & $.42-.86$ & $.11-.34$ \\
$\bar{\beta}_{\mathbf{i}}$ & 1.09 & 2.51 & 3.93 & 1.51 \\
$\sigma_{\beta_{\mathbf{i}}}$ & .165 & .304 & .475 & .267 \\
$\mathrm{E} \%$ & 15.13 & 12.11 & 12.08 & 17.68 \\
$\overline{\mathrm{X}}_{\mathbf{r}}$ & .925 & .952 & .938 & .980 \\
\hline
\end{tabular}

Note $-N=7$ for each hue.

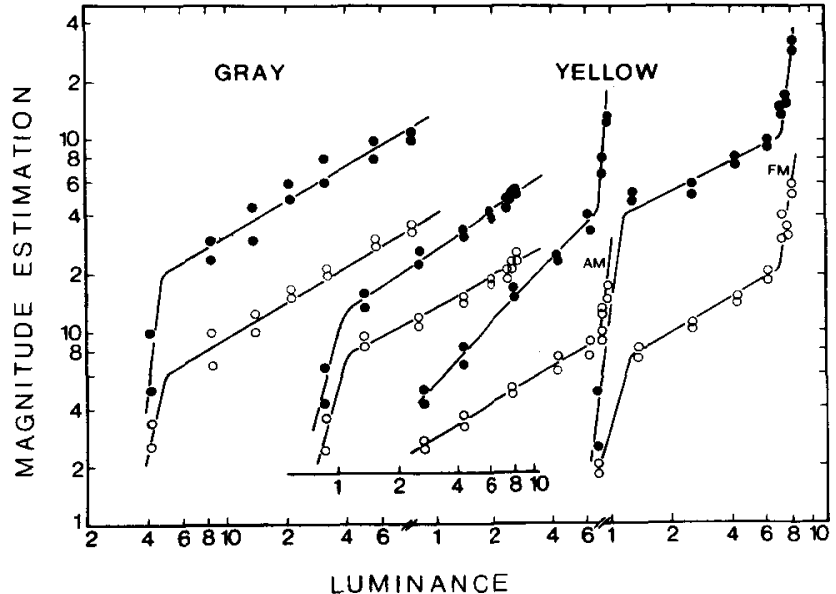

Figure 4. Individual lightness functions for grays and yellows at variable colorimetric purity. The initials indicate the observers who participated in all the experiments.

\section{REFERENCE NOTE}

1. Cross, D. V., \& Lane, H. L. Effects of training on estimates of vowel loudness. In Progress Report 2. Experimental analysis of the control of speech production and perception: II. University of Michigan, March 1962.

\section{REFERENCES}

Ekman, G., \& Åkesson, C. Saltness, Sweetness and preference. A study of quantitative relations in individual subjects. Reports from the Psychological Laboratories, The University of Stockholm, 1964, 177, 1-3.

Ekman, G., Hosman, J., \& Lindström, B. Roughness, smoothness and preference. A study of quantitative relations in individual subjects. Reports from the Psychological Laboratories, The University of Stockholm, 1964, 173, 1-13.

Guirao, M., \& Mattiello, M. Saturation scales for surface colors. Vision Research, 1973, 14, 487-493.

Indow, T., \& Stevens, S. S. Scaling of saturation and hue. Perception \& Psychophysics, 1966, 1, 253-272.

KüNNAPAS, T. Distance perception as a function of available visual cues. Journal of Experimental Psychology, 1968, 77, 523-529.

Marks, L. E., \& Stevens, J. C. Individual brightness functions. Perception \& Psychophysics, 1966, 1, 17-24.

Mattiello, M., \& Guirao, M. Lightness and saturation for surface colours. In Proceedings of the Second Congress of the International Colour Association, York, England, 1973.

Matriello, M., \& Guirao, M. Direct estimation of lightness of surface colors. Joumal of the Optical Society of America, 1974, 64, 206-209.

Mattiello, M., \& Gonnella, A. Size and desaturation scales in test for diagnosis of color vision deficiencies. In G. Verriest (Ed.), Modern problems of ophthalmology (Vol. 17) Colour vision deficiencies. Amsterdam: S. Karger, 1975.

Panek, D. W., \& Stevens, S. S. Saturation of red: A prothetic continuum. Perception \& Psychophysics, 1966, 1, 59-66.

Schneider, B., \& LANE, H. Ratio scales, category scales and variability in the production of loudness and softness. Journal of the Acoustical Society of America, 1963, 35, 1953-1961.

Stevens, J. C., \& Guirao, M. Individual loudness functions. Journal of the Acoustical Society of America, 1964, 36, 2210-2213.

(Received for publication January 19, 1976; revision accepted February $28,1977$. ) 